\title{
Bio-sociodiversidade: preservação e mercado
}

\author{
MAURO LEONEL
}

$\mathrm{E}$

NTRE Os desafios permanentes encontra-se o da estratégia adequada de uso, aproveitamento econômico e preservação do potencial contido na incomum megadiversidade brasileira, da natureza e das configurações socioculturais. A Mata Atlântica foi reduzida a cerca de $8 \%$, o que torna as precauções quanto aos recursos da Amazônia inadiáveis (Dean, 1995:361). Com destaque para a diversidade de sua flora, com 15 a 20\% do número total de espécies do planeta, 10\% dos mamíferos e anfíbios e 17\% das aves. Nas últimas décadas, as formas inapropriadas de uso dos recursos trouxeram à agenda a visão indígena e a de outras tradições locais, extrativistas, ribeirinhos, quilombolas e caiçaras. Essas contribuições ressurgem como legado exemplar, valor cultural e potencial de mercado, inclusive porque convidam a pensar e defender "uma relação positiva entre natureza e tecnologia", articulando "a necessidade de salvar bio-sociodiversidade com a necessidade de salvar também, a tecnologia”(Santos, 1999).

Os lugares mais preservados, florestas e rios, ainda coincidem com espaços interiores ocupados por índios e outras culturas tradicionais. $\mathrm{O}$ emergente biomercado e as ofertas do conhecimento cultural da biodiversidade surgem como possibilidade para novos materiais, medicamentos, princípios ativos, alimentos, perfumes, conservantes, adoçantes, sal vegetal, variedades de plantas, sementes, pesticidas orgânicos e frutas. Tal potencial remete ao tema dos direitos de propriedade intelectual de seus detentores, de seu acesso ao mercado e de sua proteção in situ, uma vez que "os serviços naturais prestados pelos ecossistemas valem mais que o PIB mundial”, lembra Novaes (1999).

Como conseguir que essas populações, e o país, possam sair ganhadores, recompensados na preservação e no mercado? As primeiras levas de ocupação do interior da Amazônia, que deram origem às comunidades beiradeiras e extrativistas, conduzidas pela mão do índio, anteriores às últimas décadas do final do século XIX, constituíram agrupamentos comparativamente em maior harmonia com o meio, herdando e acrescentando conhecimentos de manejo. Os ambientes e as sociedades interagem e modificam-se (Leonel 1998/99). 


\section{O valor do saber indígena e tradicional}

O uso indígena e tradicional dos recursos naturais contrasta com o uso destruidor dominante na recente expansão da frente econômica. Os conhecimentos da natureza demonstrados pelos índios, à medida que vão sendo revelados, chamam a atenção contraditoriamente pelo seu valor inestimável e pelo seu subaproveitamento, sendo sua relevância evidente na formação brasileira, embora inaproveitados nos projetos de colonização e assentamentos na Amazônia. Estudos das últimas décadas procuraram reunir tais conhecimentos pelas fontes históricas e pelos sobreviventes, tribos e outras culturas denominadas tradicionais, em contato maior ou menor com o mercado, ou relativamente isoladas (Ribeiro, 1987). Vários desses trabalhos evidenciam que suas premissas culturais determinam suas atividades produtivas, e que não são, como se pretendeu, apenas o resultado de estratégias adaptativas (Posey, 1984; Ribeiro, 1987).

Índios, outras populações culturalmente diferenciadas, quando isolados da pressão do mercado, que altera seu modo de vida, não são redutíveis a componentes de ecossistemas, mas ecologistas e ecólogos de pleno direito, uma vez que usaram e manejaram mais adequadamente o potencial da diversidade da natureza, controlando pragas, promovendo a heterogeneidade das espécies, vivendo sustentavelmente, sendo suas práticas flexíveis e relativas à sua visão cosmológica. Terra e território integram um mesmo tipo de espaço, onde o cultural e o econômico são inseparáveis. Esses conhecimentos e técnicas representam dimensões culturais coletivas, cumulativas e informais, não-redutíveis à propriedade intelectual privada, no sentido em que tal conceito é tratado no comércio e na jurisprudência internacional dominantes, em muitos casos, sequer se destinando à troca. No centro da sociedade Ianomami, por exemplo, encontram-se os Xaboris (pajés), conhecedores de uma droga alucinógena chamada vakoana ou ebene, retirada de uma árvore (Virola elongata) que, quando inalada, combate a doença e outras forças negativas, que ameaçam sua sobrevivência (Gray, 1991; Davis, 1993) (1).

As mudanças introduzidas em escala, com o avanço da fronteira econômica, alteram substantivamente estas relações internas às populações, e aos seus ecossistemas, impedindo idealizações. Apesar desse fato, por fazer parte do conjunto de um modo de ser e de uma visão do mundo, não caberia valorizar o saber indígena numa ótica restrita à racionalidade instrumental, reduzido a técnicas: fazem parte integrante de sua cultura, organização social, conceito de propriedade, xamanismo, língua, usos e costumes. Nem sempre toda a comunidade detém esses conhecimentos, ou os contatos com o mundo espiritual invisível, que têm papel relevante no uso dos 
recursos. Até o sucesso de uma caçada pode vir orientado pelos espíritos, em sonhos e rituais, assim como o uso das plantas e o poder de cura. O conhecimento biológico é relacionado a esse entendimento com o espiritual. Alguns pajés recebem recompensas pelos seus serviços espirituais, em sistemas de reciprocidade e redistribuição. Um conhecimento, o uso de uma espécie, isolado, levado para fora desse sistema cultural será submetido a outras regras, será transformado em mercadoria, daí as dificuldades dos temas da propriedade intelectual, das patentes e do mercado que vêm do exterior desse quadro de relações culturais específicas e diferenciadas (Shiva, 1999).

Alguns trabalhos dão conta de como os aborígenes domesticaram fauna e flora, mediante pesquisas em etnobiologia, etnobotânica, etnozoologia, etnoagronomia, e, mais recentemente, etnoecologia. A generosa natureza brasileira tem uma contribuição milenar da mão humana. Berta \& Darcy Ribeiro destacaram o manejo indígena, construindo o solo fértil pela adição de matéria orgânica nas "terras pretas", algumas imemoriais, reservas para o plantio das gerações futuras, sem perda de equilíbrio e diversidade. Esse saber contrasta com as monoculturas dos civilizados, que removem a vegetação a trator, ocasionando a erosão, a perda de nutrientes, implicando altos investimentos, energia e inseticidas, com danos ambientais e subutilização dos recursos (Ribeiro, 1987:9).

As técnicas agrícolas dos indígenas, assimiladas pelas primeiras levas de ocupação, construíram soluções adequadas aos solos pobres e lixiviados, cobertos por exuberante vegetação, combinadas com a coleta - do mel às larvas -, a caça e a pesca. Sioli (1990), mostrou como as roças de coivara, a shifting cultivation, pequenas alfinetadas na floresta, depois rotativamente abandonadas à recuperação, que ocorria em 30 ou 40 anos, eram adaptadas a solos pobres em nutrientes. Outros estudos confirmam a grande diversidade das roças de manejo indígena, inclusive nas ilhas florestadas dos cerrados, como no caso dos Kayapó que introduzem 58 espécies por roça, 17 variedades de mandioca, 33 de batata doce, inhame e taioba. Os índios conheciam utilidades para $98 \%$ das espécies identificadas, plantavam mais de $75 \%$ delas, inclusive árvores de grande porte, como a castanha-do-pará, legadas às novas gerações. Apenas $1 \%$ dessas plantas foram analisadas em suas propriedades químicas e farmacológicas. Florestas tidas como naturais podem ter sido moldadas por populações indígenas, pelo adensamento e pela diversificação (Posey, 1984; Anderson \& Posey, 1985).

Mesmo em regiões consideradas pobres em solo, com águas ácidas e poucos nutrientes, os índios acabaram conseguindo um alto aproveitamento, como no caso do Rio Negro, onde foram descritas 1.300 plantas utiliza- 
das, entre outros fins, como venenos e remédios, chegando os índios a resistir em tais regiões mais tempo e em maior número à pressão dos invasores do que em outras áreas mais férteis, desenvolvendo 100 diferentes variedades de mandioca. Morán (1990) fez um balanço das pesquisas etnoecológicas, constatando o sucesso dos índios no manejo de recursos de vários dos ecossistemas da Amazônia, inclusive transferindo conhecimentos, por exemplo, da floresta para o cerrado e vice-versa.

Nas florestas de terra firme, as mais ricas, pelo menos $11,8 \%$ seriam florestas antropogênicas, inclusive com "ilhas de recursos", com adensamento de espécies, drenagem por canais, práticas de amontoamento do solo, técnicas superiores às introduzidas pelos colonos, exemplares para a superação dos limites naturais, sem promover novos danos à diversidade. Entre as florestas manejadas cita as de palmeiras, bambu, castanhais, ilhas florestais do cerrado, caatinga baixa, cipó, várzeas, igapós e açaiçais. Várias espécies plantadas destinam-se a atrair caça, à fabricação de utensílios, alimento, lenha, colorantes e repelentes. Os colonos e técnicos, escolhendo solos inapropriados, contrastam também com o saber indígena e caboclo na escolha dos melhores solos, cerca de 7\% da Amazônia.

O conhecimento tradicional é o acumulado por uma cultura em gerações, em estreita relação com a natureza, incluindo sistemas de classificação, de zoneamento e de manejo. Embora imemorial, não deve ser considerado apenas por sua antigüidade, mas pela maneira como é usado e foi adquirido. Dutfield (1999) lista as diferenças apontadas, por acadêmicos e ativistas, entre o conhecimento científico ocidental e o indígena: tradição oral; resultado da intuição, observação e práticas; intimidade com outros seres, aos quais se consideram interdependentes e espiritualmente ligados; mais qualitativo, holístico, inclusivo e gerado por usuários; diacronicamente cumulativo e coletivo. A ciência ocidental é analítica, quantitativa, seletiva, deliberativa, sincrônica, hierarquizada, verticalmente compartamentalizada e reducionista. $\mathrm{O}$ conhecimento tradicional promove a diversidade alimentar, estabiliza a produção, diminui riscos, reduz a incidência de insetos e doenças, usa o trabalho com eficácia, exige menos insumos e recursos e maximiza o retorno em condições de tecnologias simples e adaptadas.

\section{O aproveitamento do conhecimento tradicional pelo mercado}

Alguns ecólogos propõem que, com a valorização desses conhecimentos pela pesquisa, poder-se-ia desenvolver in situ formas de aproveitamento econômico vantajosas, sem destruição ambiental, com potenciais avanços 
na química e na farmacologia, por meio de substâncias alcalóides, fungicidas e herbicidas; no aproveitamento de fibras e frutos de palmeiras, combinado com adensamento florestal. A extração de produtos renováveis, como indicam as práticas indígenas, deveriam ser consideradas, apesar do declínio de seu uso, como a seringa, a castanha-do-pará, os frutos de palmeiras e a pesca tradicional. Ao contrário, a agricultura intensiva, devido à perda de fertilizantes, não tem conseguido na Amazônia resultado econômico duradouro (Morán, 1990).

Experiências, como as asiáticas em socialforestry, com culturas perenes e anuais, consorciadas com espécies florestais, inspiradas na diversificação da cultura tradicional, começam a ser realizadas na Amazônia, como seringa com pastagem; pupunha com cacau; espécies para a produção de papel com milho e feijão. Os lucros do gado são baixos, os da madeira em tora não são sustentáveis, o que tornaria o extrativismo e o manejo diversificado do modelo tradicional potencialmente competitivo, conservando a floresta em pé. Em tal proposta aliar-se-ia preservação com objetivos sociais, permitindo o acesso ao mercado desejado por muitos desses agrupamentos e orientando os colonos. A população permanente no interior da Amazônia é menor hoje do que a das populações indígenas anteriormente à colonização, salvo nos surtos localizados de acampamento, como o do garimpo. Os sobreviventes indígenas ainda são maioria da população residente no interior em vários municípios da região Norte, sobretudo quando somados aos ribeirinhos e extrativistas influenciados pelos primeiros habitantes (Oliveira, 1988; Morán, 1990; Ab’Saber, 1996).

A coincidência da concentração da biodiversidade em territórios ocupados pelas populações indígenas, e outras culturas tradicionais de manejo, colocou o tema da preservação dos recursos da natureza como interligado à defesa dos direitos da diferença, como à terra e à cultura. Consideradas em longo prazo, essas culturas entenderam privilegiadamente que a biodiversidade, tomada como o conjunto dos recursos genéticos, espécies e ecossistemas, viabiliza a vida humana. Embora muitos índios, e outras populações, tenham se envolvido em negócios com madeireiras, garimpos, sobrepesca, entre outras atividades comprometedoras da renovabilidade e da preservação da biodiversidade, é inegável que, antes da colonização, inclusive até recentemente, pelo isolamento, antes da pressão da fronteira econômica nos últimos 30 anos, essas populações mostraram-se incomuns protetores de seus recursos, capazes de um uso adequado, orientado por seus padrões culturais.

O desmatamento, a poluição das águas, o aquecimento global, a ameaça real e imediata de comprometimento da biodiversidade articularam a sua 
preservação com o modo de vida das populações indígenas e tradicionais, colocando o tema na agenda pública internacional, embora poucas soluções abrangentes tenham dela resultado. Tal correlação tem vários desdobramentos: as áreas ocupadas por essas populações, como áreas de preservação permanente, com uso; o aproveitamento econômico dessas áreas; os direitos dessas populações à autodeterminação, tanto à terra e aos recursos naturais, quanto de acesso ao mercado, quando o desejarem; os direitos de propriedade intelectual sobre o uso no mercado de conhecimentos desenvolvidos por suas tradições; as incompatibilidades da visão indígena com as exigências do mercado, como as tecnológicas, de financiamento, de escala, de administração, de ritmo de trabalho, de apresentação do produto, de especialização e de monocultura, dentre outras diferenças culturais.

Os índios e extrativistas não aproveitaram historicamente vários dos produtos desenvolvidos por sua cultura, como no caso do ciclo da borracha: os ganhos foram para os donos dos seringais e exportadores. Com as plantações da Ásia, a exploração local dos seringais nativos teve seus preços degradados, não-competitivos sequer com as produções plantadas no Sudeste do país. Os ingleses selecionaram seringueiras no Kew Gardens (Jardim Botânico de Londres) e promoveram produções monoculturais no Sudeste da Ásia, tornando inviável a produção da borracha em escala na Amazônia, onde as "estradas" (trilhas tradicionais) têm mais distância entre as árvores, sujeitas a pragas, tornando mais difícil a coleta (Neves, 1999). Ao contrário, as atividades extrativistas levaram os índios e seringueiros à servidão, como no caso do regime de barracão, cumulativamente endividados, sem direitos à terra, aos recursos e ao resultado de seu trabalho. Quando os produtos selecionados são reintroduzidos ex situ, ou até adensados sob o controle de outros interesses in situ, os detentores desses conhecimentos não têm sua contribuição recompensada.

Organizações internacionais ambientalistas, multilaterais ou não-governamentais, vêm enfatizando como gerar lucros a partir do aproveitamento econômico da biodiversidade. $\mathrm{O}$ argumento é de que o realismo convida a demonstrar aos interesses comerciais as vantagens do desenvolvimento sustentável. A dificuldade é como introduzirem-se indígenas e tradicionais no mercado, em termos vantajosos e num quadro de livre escolha. $\mathrm{Na}$ maioria dos casos, pretende-se promover produtos aceitáveis para consumidores dos grandes centros. De saída, não é fácil atribuir valor a esses produtos, menos ainda esperar que o mercado lhes atribua qualquer compensação. Algumas projeções, feitas por ambientalistas, estimam que as grandes multinacionais estariam perdendo, com a destruição das florestas, lucros potenciais da ordem de US\$ 77 bilhões (Gray, 1991). 


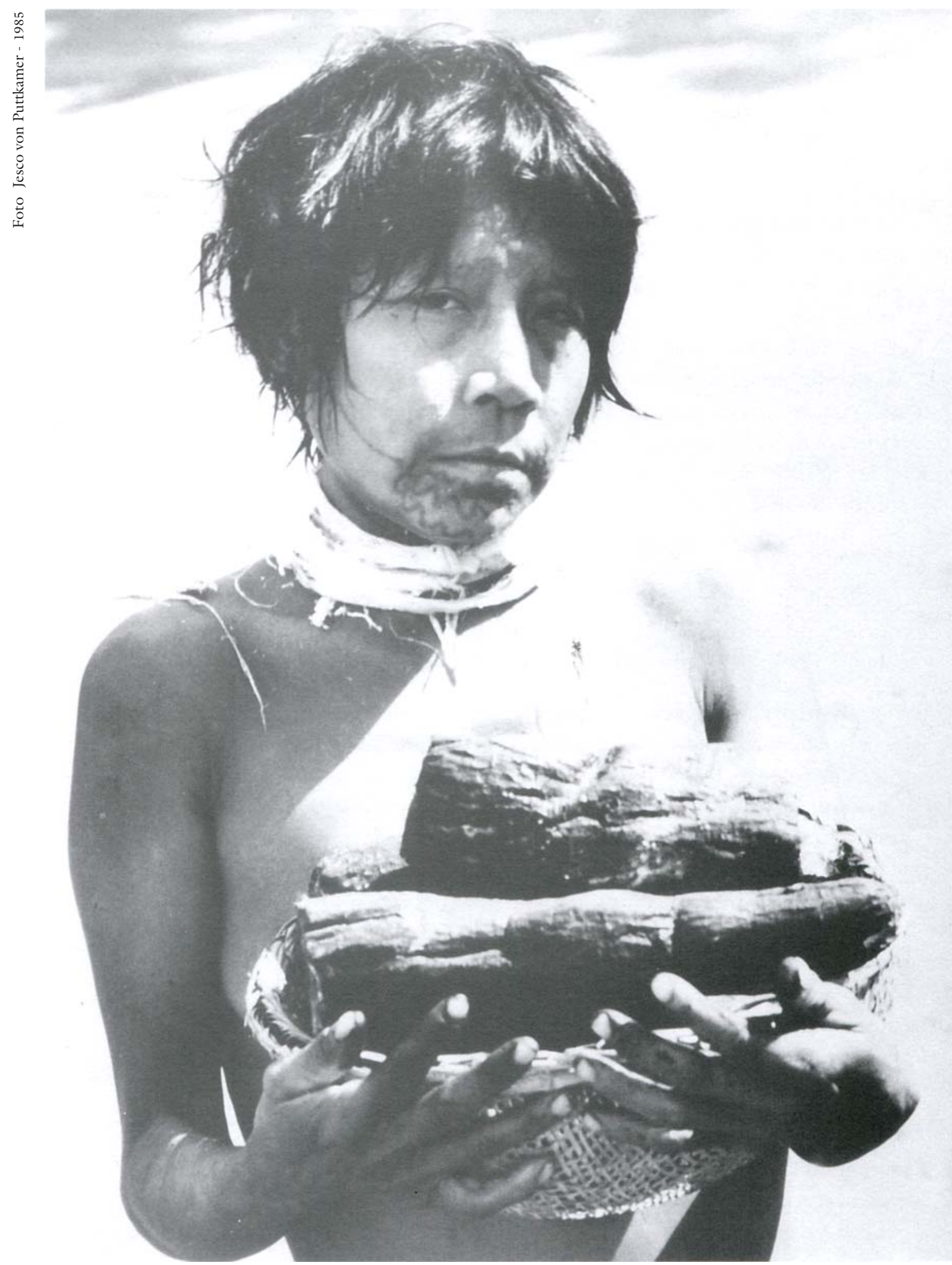

Índia Uruénauau com colar do cipó babatimão no pescoşo: analgésico contra a dor de cabeça. Esta denominação foi registrada por Jesco von Puttkamer (In memoriam). Conhece-se o barbatimão, mas é atribuido a plantas que apresentam alto teor de tanino, de ação adstringente e cicatrizante (a conferir). 


\section{Capitalismo verde \\ e projetos de desenvolvimento sustentável}

À primeira vista, é sedutora, obrigatória, ou única saída, a hipótese de aliar preservação, diferença cultural, mercado e desenvolvimento para populações que reivindicam acesso a recursos financeiros. A proposta de alguns ambientalistas é combinar a vontade manifesta eventual de algumas populações, sua contribuição à preservação, e articulá-las com o capital industrial para que saiam ambos com lucro. Não acreditam que razões apenas éticas, de dívidas sociais, possam levar à correção dos rumos de exclusão. Mas como conseguir essa parceria de contrários, evitando-se a dependência, garantindo o território, a autodeterminação, a cultura e o controle desses negócios aos mais fracos, historicamente sempre perdedores? As dificuldades são incontáveis, uma vez que o desafio seria o de rentabilizar, sem comprometer a biodiversidade, nem a livre escolha dessas populações, que sentariam à mesa com forças melhor instrumentalizadas, em posição desvantajosa, como parceiros desfavorecidos, ignorando práticas de mercado que dominam ainda menos do que os demais cidadãos, menos inclusive que outros segmentos da imensa maioria excluída, pela concentração do capital e da tecnologia, em um cada vez menor número de mãos.

Outros, mais cépticos, condicionam uma melhor relação dessas populações com o mercado a uma mudança profunda do status quo do sistema internacional, inclusive por intermédio de convenções internacionais. Alguns dando-se como tarefa provar que é de interesse público, procuram ampliar a compreensão, caminho pelo qual pretendem obter fundos, apoios técnicos não-interferentes, consumidores, parceiros e outros espaços para essas populações, contribuindo para suas necessidades e preservação da biodiversidade em maior escala. Outros, ainda mais cépticos, consideram que o problema é estrutural e tudo na concentração em curso trabalha contra as necessidades da conservação e da autodeterminação. Há dificuldades externas e internas às populações para que tais experiências se tornem eficazes, duradouras e compensatórias.

Se a biodiversidade está ameaçada, porque não protegê-la primeiro in situ? A conservação da biodiversidade, para dar-se nas dimensões amplas recomendadas pelos especialistas, implica diversas modalidades de áreas de preservação, entre elas a garantia das terras e direitos das populações tradicionais. Os chamados civilizados seriam seres sem ligação local, os da biosfera, que terminam por necessitar criar parques nacionais para compensar as atividades destrutivas de suas monoculturas. $\mathrm{O}$ velho estilo conservacionista procura remover as populações, mesmo quando mantiveram as áreas que 
habitam preservadas. Aumentam em número os que admitem que uma população possa ser parceira de projetos de conservação e qualidade de vida, para presentes e futuras gerações, interligando preservação e direitos territoriais. A proposta seria a de negociar uma política comum entre os ambientalistas e a população local, o que não se dá sem conflitos contínuos. A crítica dos ambientalistas sociais aos conservacionistas clássicos centra-se em sua excessiva ênfase nas áreas de conservação exclusivas, permitindo no máximo que os tradicionais conservem faixas do entorno, chamadas buffer areas (Gray, 1991).

Entre os próprios ambientalistas, indigenistas e representantes dessas populações diferenciadas há competição e diferenças de estratégia. Por exemplo, entre as pequenas e médias iniciativas, de grupos menores ou de populações que desenvolvem pequenos projetos, com grande carga administrativa, levados por ombros generosos, diferenciando-se das grandes ONGs internacionalizadas, que disputam projetos de maior porte, profissionalizadas, financiadas e socialmente prestigiadas. Alguns estão mais voltados a uma ação próxima de interesses governamentais e privados, inclusive com financiamento multilateral, com maior ou menor decisão, informação e participação das populações.

Gray (1991) identificou tendências entre os ambientalistas frente às populações: os capitalistas verdes, os conservacionistas clássicos e os ecologistas sociais. Os capitalistas verdes defendem que, para salvar a floresta, é preciso convencer governos, empresas e recém-chegados, criando mercados rentáveis para os produtos da floresta. Os sociais trabalham com instituições voltadas ao manejo sustentável de recursos e dão prioridade às populações. Os conservacionistas clássicos enfatizam a criação de parques e reservas mediante atividades como o turismo, ou por doações dos países mais ricos, removendo as populações. Nos últimos anos tais diferenças diminuíram e surgiram outros alinhamentos. Líderes indígenas, indigenistas, também conseguiram melhores acordos entre os defensores da inserção incondicional das populações no mercado, os que pregavam seu isolamento e os que enfatizavam a autodeterminação, tanto no controle das terras, quanto no acesso ao mercado. Mas diferenças permanecem entre as visões sociais, culturais e éticas da conservação, nas quais populações surgem como parceiros, e os que insistem na preservação como um fim em si, em áreas para pesquisa e turismo, considerando irrealista trabalhar com populações locais.

Há cada vez maior unanimidade quanto a aproveitar oportunidades de mercado, tanto via produtos quanto na conquista de compensações pela contribuição que estas populações prestam à conservação da biodiversidade 
in situ e na obtenção de financiamento. As divergências, muitas vezes ásperas, dão-se mais sobre o como fazer. Pode-se concluir que médios e pequenos projetos têm sido mais favoráveis ao controle indígena. No entanto, fracassam quando não-articulados com mudanças jurídicas e sócio-econômicas mais amplas. As bases são a autodeterminação, o autodesenvolvimento, os direitos sobre o território, a liberdade de expressão cultural, o controle do manejo dos recursos, em todas as suas fases: produção, transformação, contatos, estratégias de mercado, tecnologia, administração, distribuição da renda, escala, marketing. Tais aspectos sugerem que um aprendizado compensatório será mais efetivo com apoio técnico, desde que não interferentes ou controladores. A médio prazo, essa solução inclui a capacitação de técnicos das próprias populações, professores bilíngües, agentes de saúde e administradores, escolhidos pelas comunidades. Uma das propostas é que cada comunidade deveria contar com seu plano próprio de autodesenvolvimento, prevendo manejo diversificado de recursos, aliando auto-sobrevivência com mercado de livre escolha, mas em diálogo com especialistas que possam sugerir e oferecer suporte técnico e treinamentos. $\mathrm{O}$ acesso ao mercado traz obrigatoriamente mudanças produtivas, de difícil previsão pelo seu maior ou menor grau de incorporação, aceitação, dependência e interferência externa indesejada.

Muitos desses projetos não consideram a diversidade cultural das populações, que, apesar de coincidirem como detentores de uma dívida social coletiva, apresentam-se com sua especificidade. Os grupos indígenas no Brasil têm mais de 500 áreas, 180 idiomas e organização social diferente das de ribeirinhos, quilombolas ou extrativistas. Estudos demonstram que indígenas sempre realizaram trocas, pela reciprocidade e em espécie, inclusive rituais, entre vários grupos. Após a colonização, através de intermediários, regateiros e marreteiros que os exploravam, como no caso da borracha, entregavam o produto e seu trabalho a baixo custo, sempre "devedores", contraindo novas doenças, perdendo terras e recursos. Experiências mostram que o conhecimento não retorna vantajosamente aos tradicionais, quando posto sob o poder concentracionário de interesses financeiros externos, industriais ou do agribusiness, a partir do maior controle do acesso à informação, à tecnologia, ao capital e à escala de produção. Os produtos que realmente poderiam ter bons resultados financeiramente, são os que menos essas populações estão preparadas para administrar, os mais interferentes e predatórios, como os farmacêuticos, sementes, material genético, madeira nobre, mineração, ecoturismo, atividades ligadas a esferas e circuitos complexos do mercado, com maior risco de imposição de uma concepção exterior de desenvolvimento e de queda de qualidade de vida. 
Nos projetos de registro de patentes e produção ex situ da biodiversidade, os nativos servem como informantes, colaboradores na seleção de dados, mas raramente são os que compilam, sistematizam e controlam o aproveitamento desses dados (Dutfield, 1999; Shiva, 1999).

Algumas experiências de saídas econômicas, apresentadas como compensatórias, são até mais modestas, como a venda de farinha para o mercado mais próximo, a exemplo dos índios do Mamoré, fornecendo à cidade de Guajará-Mirim. O mais freqüente é que consigam colocar ocasionalmente seus produtos em feiras locais. Dessas soluções resulta a oferta de excedentes de sua produção rotineira para a auto-sobrevivência, como o artesanato, a pesca, a farinha, e não novidades escolhidas pelo seu valor de mercado, mas produções variadas de pequena escala, levadas por famílias ou aldeias, ampliando o acesso de seus excedentes no mercado regional.

Parte dos projetos voltados a essas populações não se mostraram compensatórios, nem garantiram autonomia e livre escolha. A advertência de algumas vozes representativas dos índios e indigenistas, como de outros desfavorecidos pela diferença cultural, é de que, em geral, as populações são tratadas como vítimas passivas ou simples receptáculos de projetos impostos de cima. Muitas vezes os proponentes partem de uma visão bem-intencionada, mas paternalista e economicista, que não leva em conta a especificidade cultural, os direitos à autodeterminação, opções diversificadas, sequer as produções costumeiras, voltadas à auto-sobrevivência e ao autoabastecimento. A tendência é de que a monocultura se imponha, privilegiando produtos não-sustentáveis, diminuindo sua autonomia e assimilando valores exteriores às suas tradições. Outros chegam a controlar a produção, impondo concepções de desenvolvimento, sejam de interesses privados, técnicos do Estado, religiosos, conservacionistas e ONGs indigenistas. Tais iniciativas tendem a soluções monolíticas e monoculturais, precárias, sazonais, produções sujeitas a preços instáveis, ameaçadas por desmatamento e pragas, como nos casos da pesca, seringa e castanha. A dependência vai aumentando por prazos, transporte, armazenamento, apresentação, marcas, tecnologias de transformação, escala e agregação de valor. Populações comprometeram assim o seu modo de vida, sem vantagens, ao aceitarem, por necessidade, pressões pelo consumo de seus produtos, incorporando novos métodos, inclusive no trato de espécies que manejam tradicionalmente.

\section{A livre escolha das populações tradicionais}

Uma das propostas refere-se a que essas populações criem suas próprias instituições controlando seu conhecimento, com o apoio de pesquisa- 
dores, acordos sobre royalties, negociando autorizações e compensações. Nem todos julgam obrigatório o acesso às patentes; a informação poderia ser aberta, mas seu uso controlado e as compensações acordadas, desde que capazes de decidir, porque autônomos e informados. Recomenda-se que partam do mercado local e regional, para as esferas mais amplas do mercado, como o nacional e o internacional. Suas próprias instituições encontrariam canais para acessar o mercado, com marcas próprias, selos verdes e certificados de origem, com banco de dados registrando a informação e a produção que possam oferecer. Os defensores do capitalismo verde procuram espécies para o mercado, pretendendo "descobri-las", mas as minorias têm se saído melhor in situ do que ex situ. Esse reconhecimento, por meio dos produtos, contribuiria para o respeito e a tolerância com as culturas diferenciadas e com maior sabedoria e conhecimento sobre o manejo das florestas (Gray, 1991).

O financiamento de projetos governamentais e privados pode resultar no fomento ao individualismo, aumento da desigualdade e de conflitos, com quebra não compensatória dos laços tradicionais de reciprocidade. Experiências revelaram dificuldades de representação dessas populações, a ser sempre conferida e legitimada. No caso dos índios, dada sua diversidade, é importante garantir que a representação seja proporcional e pluriétnica, quando se trata de organizações regionais ou intergrupos. Há conflitos entre as formas tradicionais de organização social, nos quais os mais velhos desempenham papel fundamental, enquanto novas formas organizativas, de inspiração sindical ou partidária, lideradas por pioneiros mais jovens, desenvoltos na cultura majoritária, mas que nem sempre garantem formas de distribuição compensatórias aos mecanismos culturais de reciprocidade. A dificuldade advém do fato de se considerar a organização de representação política dessas populações como capaz de conduzir também projetos econômicos, quando os produtores ativos estão ligados aos conselhos tradicionais de aldeias, às famílias ampliadas e aos laços de parentesco, e não aos líderes reconhecidos externamente, que muitas vezes residem na cidade, alguns prestando serviços reais, outros em situação socialmente precária.

Algumas iniciativas têm levado também à criação de facções nas comunidades, não considerando as divisões internas já existentes, ou intergrupos, e agravando-as. No caso de jovens lideranças indígenas que entraram ilegalmente em negociação com madeireiras e garimpos, freqüentemente urbanizaram-se, comprometeram-se em casamentos mistos e em outras relações de dependência, perderam muitos de seus laços, não souberam fazer uso dos recursos a longo prazo, nem os redistribuíram adequadamente aos seus. As mulheres, as crianças e os idosos terminaram sem as garantias da 
reciprocidade, não participaram dos ganhos dos negócios realizados pelos homens em suas novas alianças e suas aldeias foram faveladas, aumentando a desnutrição e as doenças.

Muitos projetos inspiram-se em visões comunitaristas, como se os índios estivessem disponíveis culturalmente para formar cooperativas igualitaristas, o que não coincide com os fatos, nem com as tradições. A produção de grande número desses agrupamentos tem como base o parentesco e a cooperação no trabalho, o que não se confunde com coletivismo, pois ali se sabe o que pertence a cada um, apesar de os recursos encontrarem-se mais disponíveis ao uso comum do que na cultura majoritária. Embora fundados na solidariedade e reciprocidade, não existe socialização da produção, nem a predisposição idealizada por bem-intencionados. Com a pressão do exemplo dos colonos vizinhos, ao contrário, sobretudo entre os mais jovens, muitos querem ver dinheiro vivo e imediato, cuja redistribuição não é automática, nem mantida nos padrões de reciprocidade da tradição. Produtos de fora chegam com regras de mercado introduzidas pelas práticas regionais, das mais precárias na fronteira. O que se assiste é à subalternização pelos intermediários, mais conhecedores da dinâmica do mercado, capazes de manterem contato com os consumidores distantes. Essas populações precisariam controlar coleta, produção, extração, transformação e comercialização, mesmo perdendo aparentes grandes negócios que não são os seus.

Dutfield (1999) recapitula o debate entre os que defendem os tradicionais como preservacionistas éticos e os que consideram que esta ética não pode ser generalizada, pois prevaleceria apenas quando estão isolados em grupos menores. Lembra os cépticos quanto "aos selvagens ecologicamente nobres", e os que consideram perigoso e injusto impedir-lhes o acesso a novas tecnologias, condenando-os apenas às tradicionais, de menor impacto, mas limitando suas estratégias de sobrevivência.

\section{Etnomedicina e etnofarmacologia}

Três quartos das drogas utilizadas pelo receituário médico derivam de plantas descobertas pelo conhecimento indígena. De 120 componentes ativos isolados de plantas, $75 \%$ têm origem em seu uso tradicional. Plantas tradicionais foram utilizadas em sete mil componentes da farmacopéia em uso. O aproveitamento da biodiversidade no mercado transformou-se em um negócio expressivo: a venda de medicamentos derivados de plantas nos EUA, em 1990, já alcançava US\$ 15.5 bilhões. Em 1985, somando-se EUA, Europa, Canadá, Austrália e Japão, esse mercado movimentou US\$ 43 bilhões. Especialistas destacam a relevância do conhecimento indígena, como quinino, para malária; curare, relaxante muscular; hormônio esteróide 
diosgenin, nas pílulas anticoncepcionais; vincristine, usada na cura do mal de Hodgkin e na leucemia. No início da década, o Instituto Nacional do Câncer dos EUA desencadeou uma pesquisa procurando plantas para quimioterapia em todo o mundo (Gray, 1991; Davis, 1993; Nijar, 1999). O Instituto Nacional de Saúde dos EUA tem um estoque de germoplasmas, armazenados criogenicamente, que permanecerão disponíveis por 350 anos. Os resultados do conhecimento tradicional foram apropriados como tecnologias patenteadas, sem o consentimento ou a adequada compensação aos que o desenvolveram, como no caso da morfina ou do quinino.

Algumas iniciativas pretendem compartir com os índios os lucros de sua medicina no mercado. Na Califórnia, a Shamam Pharmaceutical Inc. se propôs a remunerá-los pela coleta, cooperação na taxinomia das plantas e pela propriedade intelectual. A empresa encontrou, em 1999, dificuldades para a aprovação de produtos pela FDA-EUA (SP-303-Provir), devido aos custos dos estudos clínicos exigidos. Em 1998, foi criada também a Shaman Botanicals, voltada a produtos alimentícios, selecionados a partir de estudos etnobotânicos. Foram recebidos com ceticismo pelo mercado e com desconfiança por alguns ambientalistas e pesquisadores. A Merck and Co., Inc. fez um acordo semelhante com a organização de pesquisas INBio e comunidades da Costa Rica (Davis, 1993:19).

Organizações indígenas da Amazônia (30/3/99), com o apoio de entidades ambientalistas, ingressaram com um pedido pela anulação da patente ${ }^{\circ}{ }^{\circ}$ 5751, da planta "ayahuasca" ou "yagé"(Banisteriopsis caapi), registrada por Loren Miller, em 1986 (2). O argumento, apresentado ao Patent and Trademark Office dos EUA, é de que a planta é usada pelos pajés da Amazônia em cerimônias religiosas de cura, para chamar os espíritos e para prever o futuro, devendo ser cuidada e usada com respeito e precaução. $\mathrm{Na}$ petição, solicita-se que o serviço de patentes cuide de registrar apenas produtos aos quais se acrescentou conhecimento, o que não vem ocorrendo com plantas de uso tradicional. O registro aceita como propriedade particular de qualquer um, conhecimentos que pertencem há gerações a outras culturas, quebrando a exigência de que a patente caracterize inovação. A solicitação pretende que o serviço de patentes garanta contribuições aos povos indígenas, incentivando a conservação dos sistemas tradicionais de conhecimento da biodiversidade, equilibrando os benefícios entre os operadores no mercado e os detentores do conhecimento por tradição de uso. Um exemplo é o do anticoagulante retirado da planta "tike uba" (3), usada pelos Uruéu-au-au (RO), contatados na década de 80, que foi entregue para análise a grandes empresas, sem retorno ou controle previsto à população que a desenvolveu (Gray, 1991:46; Leonel, 1995). 
Um químico francês coletou dos índios Chimanes da Bolívia, o pó da casca da espécie da floresta tropical Phlebotomus, identificou a planta (Galipea longiflora), usada tradicionalmente no tratamento da Leishmaniose, patenteou-a, isolou seu princípio ativo e pesquisou sua eficácia. O produto ainda não foi fabricado por seu alto custo ao consumidor e à exigência de pesquisas clínicas. Os bolivianos protestam porque os índios não foram associados à patente. Como a pesquisa foi financiada pela cooperação técnica francesa, busca-se parceiros privados e formas jurídicas para reconhecer os direitos dos índios, caso se torne um produto rentável no mercado (Tardieu, 1999). Os Wapixana (RR) denunciam um químico alemão, Conrad Gorinski, filho de uma índia, pelas patentes nos EUA e na Europa de duas plantas de uso tradicional: uma para a pesca, o cunani, que poderia ser usado como anestésico; outra, tibiru ou rupununi, um remédio tradicional, que poderia ser aproveitado no tratamento de tumores, malária e como anticonceptivo.

\section{Biotecnologia, biopirataria, patentes e conhecimentos tradicionais}

A chamada "revolução verde" é citada como advertência e precedente da exclusão das populações (Escuret, 1989; Gray, 1991; Nijar, 1999). A produtividade por hectare de grãos selecionados foi dobrada nos anos 80 , a área cultivada aumentou em $24 \%$, com alto custo em energia, insumos, máquinas, combustíveis, fertilizantes, pesticidas, herbicidas, irrigação, eletricidade, transporte e impactos sobre a disponibilidade de terra e água.

Espécies foram selecionadas para monoculturas em escala, como milho, arroz e batata. Sete cereais passaram a totalizar metade das calorias da população mundial. Ao invés de compensações por sua oferta de biodiversidade, adquiriram novas espécies selecionadas, mais eficientes por hectare, porém mais expostas a pragas e parasitas, sem a garantia de substituição oferecida pela diversidade. Esses ganhos de curto prazo foram localizados, para grandes produtores, enquanto os pequenos endividaram-se e perderam terras.

A "revolução verde" foi patrocinada por uma rede, a International Agricultural Research Centers, coordenada pelo Consultative Group on International Agricultural Research (CGIAR), criado em 1970, pelo Banco Mundial. Promoveram-se coleções e bancos de conservação de recursos genéticos, selecionando espécies, desestimulando a diversificação, criando monopólios das sementes mais resistentes aos herbicidas. Muitas espécies têm sido retiradas para conservação fora de seu local de origem, para pesquisa, verificando-se as condições de aproveitamento em outros locais, ou 
desenvolvendo-se novas variedades. O CGIAR e a FAO criaram uma instituição voltada para a conservação e pesquisa de recursos genéticos, o International Bureau for Plant Genetic Resources (IBPGR), que centralizou, no início da década, 127 coleções de material genético, com 81 delas em países do hemisfério norte e 29 controladas por multinacionais. Apenas 17 encontravam-se em países do Terceiro Mundo, apesar de a maioria das espécies ter sido neles coletada.

Estoques, em baixas temperaturas secas, foram conservados em 227 bancos de sementes, em 99 países. Poucas espécies foram destinadas a serem preservadas in situ, como o amendoim, o óleo de palmeira, a banana, a borracha, o café, o cacau, a cebola e os cítricos.

Alguns conservacionistas entendiam que essa era uma das formas de manter vivas as opções, argumentando que a proteção de espécies da natureza oferece tantas alternativas e tantos avanços quanto a biotecnologia. Os sociais defendiam a prioridade à proteção in situ, com a participação das populações detentoras do conhecimento, pois consideram que, de outra forma, os resultados serão semelhantes aos da seleção para monoculturas da "revolução verde", dominadas por um pequeno grupo de grandes empresas, controladoras de direitos e informações (Gray, 1991). Em 1996, o CGIAR contou com US\$ 300 milhões para renovar seu programa, levando agora em conta populações e ecossistemas, e denunciando patentes vindas dos bancos de germoplasma de acesso público.

Dutfield (1999) adverte que há dúvidas de que estes "arquivos" possam se manter atualizados, uma vez que o conhecimento tradicional evolui, e, fora de seu contexto, perde vitalidade. A pesquisa para patentes que não reconhecem os direitos das populações vem sendo recebida com reservas de ordem ética, ao valorizar e apropriar o conhecimento, excluindo dos benefícios as populações detentoras. Vários programas enviam pesquisadores para selecionar amostras e descrições de uso. Os recursos dos ecossistemas tropicais são considerados herança da humanidade, sem dono, livres para patente e comercialização. A partir do processamento de amostras, a "descoberta" é patenteada, os direitos passam para a empresa financiadora, protegidos como mercadorias.

A "revolução verde" consistiu na manipulação genética pela seleção de plantas. A biotecnologia atravessa a barreira das espécies, recria, modificando a partir de organismos vivos, por técnicas diversas, obtendo novas espécies de interesse comercial. A biotecnologia apresentou-se como promessa de solução à escassez de alimentos. Enquanto a "revolução verde" dependeu de fundos públicos, a biotecnologia é dominada pelas grandes 
corporações multinacionais, que definem a agenda das pesquisas, financiando universidades e centros de pesquisa (Gray, 1991).

As patentes estão no centro do controle concentracionário permitido pela biotecnologia, com a cobrança de direitos sobre formas de vida modificadas. $\mathrm{O}$ dono da patente tende a liderar o mercado e as futuras inovações, inclusive as dos detentores originais do conhecimento de seu uso. A conceituação desses produtos como novidades, pela criatividade e uso prático, condição para ser registrada, vem sendo questionada quanto à sua ética e à sua lógica, uma vez que nada na natureza é estritamente inventado, e o que se tem feito é modificar. Para todos os agricultores é um impasse, pois não poderiam usar mais as espécies com elementos genéticos patenteados. Os EUA e a Europa admitem legalmente tais patentes, e embora com discrepâncias, o sistema é unificado. Os países em desenvolvimento tentaram, por intermédio da FAO, impedir que o controle ficasse apenas com os que detêm tecnologia, em prejuízo dos detentores originais. Procura-se garantir as operações das multinacionais além fronteiras, com desvantagem para os países que não detêm tecnologia, dificultando o acesso a produtos, bloqueando sua capacidade de inovação e competitividade, inclusive quando os conhecimentos têm origem em suas próprias populações.

De início, a propriedade intelectual foi discutida quanto aos direitos dos conhecimentos informais de agricultores como um todo. Com a entrada no debate da oferta de plantas da biodiversidade tropical, o tema tocou mais de perto as populações tradicionais. Pesquisas em curso voltam-se para conservantes e inseticidas naturais. Chegou-se a reivindicar que direitos sobre variedades de mandioca, batata, tabaco, quinino, curare e milho fossem então reconhecidas aos tradicionais. Os ambientalistas comerciais são criticados por encorajarem as empresas a desenvolverem superespécies, selecionando-as ex situ, promovendo monocultura, sem garantir os direitos das populações. Os países do Sul perderam com a "revolução verde", seus povos tradicionais e pequenos produtores, perderão ainda mais com a biotecnologia.

A tônica internacional é a do descolamento e de contradições entre os acordos e fóruns de negociações, separando-se temas inter-relacionados, como a conservação da biodiversidade, os direitos e conhecimentos das populações e os interesses das grandes corporações em garantir lucros sobre tecnologias. Nos últimos anos, alguns discursos pareciam se aproximar, mas não há medidas efetivas que possam ser comemoradas. O princípio de que a preservação da biodiversidade é inseparável da cultural tornou-se mais aceito, mas são poucas as parcerias entre populações, ambientalistas, governos e setor privado. Em geral, os direitos das populações à biodiversidade vêm 
sendo discutidos como temas éticos e sociais, em convenções da OIT, da FAO, na convenção da biodiversidade, em grupos de trabalho da ONU. Os interesses das grandes empresas, na forma de patentes e propriedade intelectual são tratados no GATT e na OMC como direitos comerciais. A tônica é a de sempre: os países tropicais oferecem livre acesso aos conhecimentos de uso da biodiversidade, os do Norte cobram tecnologia. Na lógica de propriedade e mercado que construíram, concentracionária e hegemonicamente, os conhecimentos da biodiversidade são patrimônio da humanidade, de livre acesso, não contabilizáveis, mesmo que regressem aos países de origem na forma de mercadorias.

A Convenção Internacional da Biodiversidade reconheceu a soberania dos países sobre os benefícios e os recursos de sua biodiversidade; recomendou proteção aos direitos e conhecimentos das populações tradicionais quanto a seus recursos; previu legislações nacionais sui generis garantindo estes conhecimentos; incentivou a proteção de tecnologias informais e o uso sustentável da biodiversidade. Os EUA isolaram-se frente aos 169 países que ratificaram a Convenção. Dutfield (1999) considera positivo que a convenção tenha conceituado os conhecimentos informais como inovações e práticas tradicionais, retirando-lhes a carga de saber datado, histórico, inflexível e estático.

A jurisprudência internacional reconheceu a propriedade intelectual quanto a criatividade e inovações das empresas, pelas patentes, mas não a informal, tradicional, coletiva ou intergeneracional. O resultado, argumenta Nijar (1999), é que as empresas continuarão a visitar populações tropicais, reclassificar, transformar e patentear materiais genéticos do uso tradicional da biodiversidade. A Union for the Protection of New Varieties of Plants (UPOV), em convenções (1961/1991), tratou das espécies consideradas identificadas, homogêneas e estáveis, protegendo os selecionadores, em prejuízo dos conhecimentos informais. Com as patentes, os grandes podem investir em novas variedades, enquanto as populações tradicionais, mesmo que cumulativamente tenham desenvolvido esses produtos, foram marginalizadas da competição. Apenas a última contribuição tecnológica é protegida, a de grandes empresas, que podem controlar as variedades subseqüentes (Gray, 1991; Nijar, 1999).

O acordo patrocinado pela OMC - Organização Mundial do Comércio, o TRIPS - Trade Related Intellectual Property Rights, fortaleceu o sistema de patentes. Os EUA e a Europa consideram que os conhecimentos tradicionais não cabem na lógica de propriedade e patente do TRIPS, mas em sistemas como a UPOV, articulados com a convenção da biodiversidade, ou similares, a serem criados, mas menos efetivos (Nijar, 1999). 


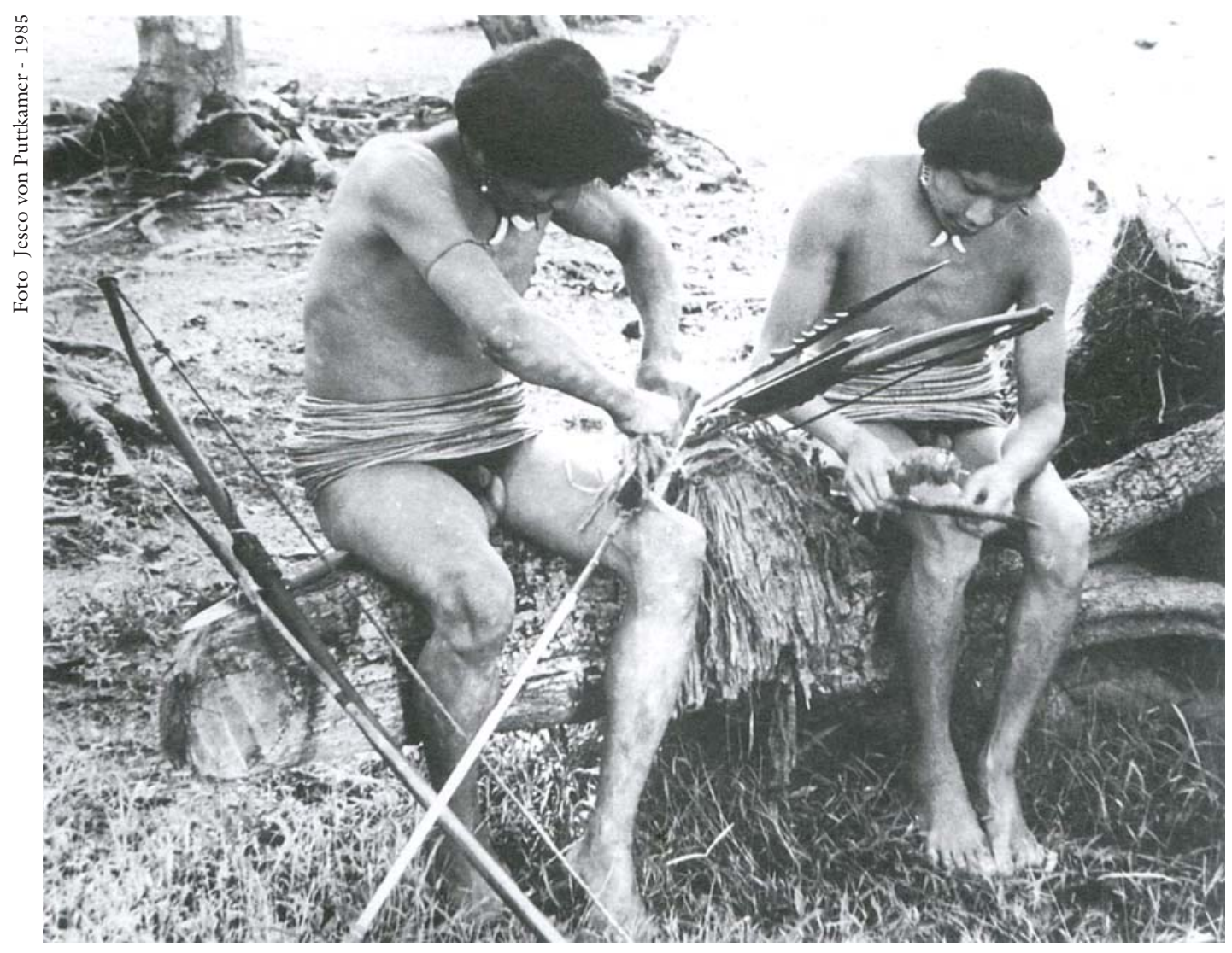

Índios Uruéuauau passando nas flechas líquido anti-coagulante chamado Tike-Uba

O Grupo de Trabalho da ONU sobre populações indígenas, em 1990 já reivindicava medidas de proteção da propriedade intelectual para manifestações culturais, entre elas literatura, desenho, artes visuais, performing arts, sementes, recursos genéticos, medicina e conhecimentos de uso de propriedades da fauna e da flora. Davis (1993:20) manifestou-se céptico quanto à possibilidade de que a revolução biotecnológica, mesmo com o reconhecimento da propriedade intelectual, pudesse por si só garantir prosperidade econômica para populações indígenas e comunidades rurais tradicionais.

A visão dominante é economicista, voltada às espécies rentáveis e à lógica do mercado, contraditória inclusive em documentos que afirmam ser impossível salvar uma espécie, sem preservar grandes porções dos ecossistemas, e nos que reconhecem as dificuldades de aproveitá-las em todas as suas potencialidades $e x$-situ, por interromper o saber cumulativo de seu uso contínuo. A prioridade ao mercado é redutora do ambiente a um conjunto quantitativo de recursos, listas ou inventários de espécies e usos, separadas das inter-relações culturais entre sociedades e naturezas, das exigências da 
própria natureza, evitando articular as questões. As populações chegam a ser vistas como mais um grupo de interesses, o das minorias, que seriam potenciais predadores, semelhantes às agropecuárias, mineradoras, madeireiras e colonos, pois terminariam por aceitar a compensação do lucro pela degradação. Os ecologistas sociais respondem que é preciso garantir-lhes as condições de autoabastecimento e compensações pela preservação.

Uma das tentativas iniciais foi a da troca de títulos da dívida externa por áreas de preservação, com experiências na Costa Rica e na Bolívia. Esta alternativa serviu para algumas experiências de parques conservacionistas, mas não tanto para as populações tradicionais. Na última década investiu-se em projetos florestais de captação de carbono, em sua maioria plantios de interesse das indústrias de papel, sem a participação das comunidades, privilegiando poucas espécies e carentes de uma visão de socialforestry. Gray (1991) estimou que sobrevivem cerca de cinco mil minorias culturais, 200 milhões de pessoas, $4 \%$ da população mundial, localizando-se em sua maioria na Ásia, nas ilhas do Pacífico, entre os pastores e coletores da África, nas Américas, representando $90 \%$ da diversidade cultural do planeta.

\section{Propostas para superar}

os impasses das negociações internacionais

A proposta de especialistas, reunidos em 1997 pela convenção da biodiversidade, foi a de moratória da coleta de conhecimentos tradicionais, até sua proteção. Chegou-se a propor que o material biológico em geral deveria ser excluído dos direitos de propriedade intelectual, por razões éticas, pelas diferenças culturais e pela ameaça à biodiversidade. A Sociedade Internacional de Etnobiologia condiciona as pesquisas ao consentimento informado das populações. Os críticos do reconhecimento da propriedade intelectual informal argumentam que constituiria uma limitação ao acesso às heranças da humanidade, além de forçar comunidades a agirem na ótica das empresas privadas, porque o conhecimento tradicional é considerado bem coletivo e a tecnologia privada.

Outras soluções têm sido consideradas, como a do registro de espécies, por sistemas próprios de cada país, antes que elementos genéticos da sua composição venham a ser patenteados. As leis de copyright referem-se à reprodução de obras de arte, de material escrito ou visual. Os mecanismos de licenciamento de tecnologia, como o de patentes, tratam de direitos individuais e não coletivos. Especialistas recomendam tentar todas as opções: cultivares, patente, copyright e licença tecnológica, embora tais instrumentos não sejam adequados às necessidades e concepções das populações 
tradicionais. O Brasil nos últimos anos promulgou a lei de proteção de cultivares, atualizou a lei de direitos autorais, que não considera invenção os materiais biológicos, mesmo isolados, embora permita a patente dos trangênicos. Os bens culturais também são difíceis de proteger contra abusos e descaracterizações, pois é preciso, ao mesmo tempo, encorajar novas criações, apoiar a disseminação, adaptações em obras de autor, e condicionálas à autorização das autoridades nacionais e das comunidades. Esforços têm sido feitos para aumentar garantias às minorias, por intermédio da World Intellectual Property Organisation, com sede em Genebra (Gray, 1991; Nijar, 1999).

Para garantir os direitos de tradições informais - fora do TRIPS e da UPOV - restam as leis nacionais, acordos de reciprocidade bilateral, novas convenções, ou recorrendo-se a razões éticas ou de interesse público para anular patentes. O conceito de inovação, pouco claro, daria espaço a que cada país estabeleça seus critérios. Nos EUA, uma forma isolada e processada, pode ser patenteada, mesmo quando encontrável na natureza. Os europeus permitem patentes de estruturas e processos de obtenção, desde que não sejam de domínio público. Outros países, por leis próprias, poderiam reconhecer direitos de tradições, recusar o registro de patentes genéticas, ou combinar patentes com outras modalidades de proteção, equilibrando direitos das empresas com os dos tradicionais. No Brasil o Congresso discute a regulamentação do acesso ao patrimônio genético, a partir da proposta da senadora Marina Silva (PT-AC).

Outras experiências envolvem parcerias com pesquisadores locais e as comunidades, o que é visto como uma iniciativa de instituições e de empresas farmacêuticas dos EUA de aplicar princípios da convenção da biodiversidade, mesmo sem ratificá-la, como a Bristol Myers Squibb, no Suriname. A dificuldade é que sequer os pesquisadores brasileiros estão preparados para estas negociações, o que traz cepticismo quanto à possibilidade de que os índios e outros tradicionais possam fazê-lo (Kauffmann-Zeh, 1999). A Glaxo Wellcome fez um acordo com a empresa brasileira Extracta, para a prospecção de 30 mil compostos, a um custo de US\$ 3,2 milhões, 18\% para subcontratos com cientistas brasileiros, mas a notícia não esclarece se os direitos das populações estão previstos (FSP, 20 jul. 1999:13-21). Cientistas estrangeiros acusam os brasileiros de bioparanóia, advertindo que pesquisarão em outros países e que o Brasil sairia prejudicado, pois apenas 10\% das espécies da Amazônia seriam conhecidas.

Na proposta de Nijar (1999), leis nacionais poderiam condicionar as patentes ao consentimento informado das populações; proibir o registro de derivados do conhecimento tradicional; desobrigar as populações de regis- 
trar conhecimentos, sendo suficiente a prova de uso tradicional; aplicar como único critério de registro o da UPOV, em variedades identificadas, uniformes e estáveis; desobrigar pequenos e minorias de respeitar patentes; restringir o conceito de variedade derivada; incentivar a conservação local de sementes; por precaução, recusar registros que possam vir a afetar a biodiversidade, a saúde, ou quando a variedade não tem capacidade regenerativa normal ou prejudica sócio-economicamente o país ou comunidades. Propõe ainda que os temas relativos à biodiversidade e às populações passem a ser tratados pela convenção da biodiversidade e não pelos acordos comerciais.

Dutfield (1999) argumenta que há vários domínios privados de conhecimentos, não previstos nas convenções, que consideram apenas um tipo de propriedade intelectual, o empresarial-comercial dominante. Para os direitos de populações tradicionais, seriam necessários novos instrumentos jurídicos, fundados nos direitos de detentores de conhecimentos resultantes de práticas coletivas, consuetudinárias ou costumeiras, com prioridade para conhecimentos ainda não de domínio público e futuras inovações informais. Assim, quando um conhecimento fosse colocado no domínio público, sem o consentimento de seus detentores, estes deveriam poder recuperar sua titularidade e direitos de indenização, pelo mesmo princípio da patente, que é o de estimular a criatividade. Tais direitos diferenciados deveriam ser reconhecidos não apenas pelo seu valor instrumental, mas também pela contribuição das culturas minoritárias e por razões éticas. A troca de bioprospecção por tecnologia, associação nas patentes e combinação de royalties com pagamentos antecipados na coleta são outras propostas formuladas. Fato é que as lógicas da ciência e do mercado diferem dos sistemas tradicionais de conhecimento, na concepção de propriedade, e há forte ceticismo quanto ao reconhecimento de direitos de populações, ou outros que se encontrem fora dos interesses das grandes empresas que concentram capital e tecnologia.

Algumas das alternativas implicam modificar as leis de patentes, outras combinam soluções, como certificados de origem dos produtos, marcas ou selos próprios de populações, com indicações geográficas e culturais de origem como saídas para que países tropicais incentivem compensações aos conhecimentos de suas populações tradicionais. Poderiam ser exigidas, para o registro de patentes, declarações de que produtos genéticos não receberam qualquer contribuição anterior de populações tradicionais, ou evidências de que houve o seu consentimento informado e de que participariam dos lucros. Sistemas especiais de certificação e padronização podem garantir às comunidades poder de veto ao acesso e uso de seus recursos. Mesmo que várias dessas iniciativas fossem tomadas, como os tradicionais venceriam no mercado? 
Outra linha de alternativas, não apenas jurídicas, mas de defesa da biodiversidade e dos tradicionais in situ, pretende fortalecer as próprias comunidades para que possam tratar seus conhecimentos como segredos comerciais, capacitando-as para obter benefícios da bioprospecção, inclusive para patenteá-las. As comunidades criariam seus próprios bancos de dados, com acesso reservado, identificando conhecimentos que já caíram no domínio público e os partilhados por mais de uma comunidade. Para evitar conflito de interesses nos casos em que há várias comunidades detentoras, seriam formados cartéis e negociados acordos entre governos e comunidades. Bancos de dados de conhecimentos informais foram iniciados no Equador e na Índia. Outros propõem que as autoridades tenham acesso aos dados, reconhecendo os conhecimentos tradicionais que possam ser confirmados como novidade ou invenção. Dutfield (1999) considera que restrições ao acesso à informação, se por um lado podem impedir abusos, por outro a transparência dos bancos de dados contribuiria para coibir ou anular patentes, por exemplo, de uma planta medicinal indígena, desde que a justiça considere as contribuições informais anteriores ao produto patenteado e aprimore o conceito de domínio público. Em muitas das alternativas, o que se busca é adequar o conhecimento tradicional à lógica de propriedade privada do mercado.

A própria diversidade das populações detentoras destes direitos é usada como argumento para adiar o seu reconhecimento. Em algumas tradições, o próprio conceito de propriedade é alienígena, pois sua ética compartilha conhecimentos; em outras, há sistemas específicos de propriedade, com jurisprudência própria. Segredos teriam existido desde tempos imemoriais dos caçadores e coletores, comparáveis aos segredos comerciais contemporâneos, porque podem ser trocados, vendidos, comprados, inclusive os medicinais. Muitos pajés detêm conhecimentos exclusivos de cultivares, coletas e usos para cura. Certos conhecimentos foram geográfica e transculturalmente disseminados, não sendo fácil identificar o titular coletivo ou individual desses direitos, mesmo quando tais conhecimentos podem ser atribuídos a uma comunidade ou a um grupo de parentesco, ainda assim surgem dificuldades, como as do custo para registrar e garantir a patente da pirataria, além do risco de o investimento ficar sem retorno.

A vantagem das empresas é a de que dispõem de um só sistema de patentes, baseado na propriedade privada de tecnologia. Seu fundamento é de que os direitos decorrem do aproveitamento comercial e técnico, diferente do conhecimento tradicional, do qual dependeriam cada vez menos para agregar novas inovações. $\mathrm{O}$ fato de haver comunidades que consideram seus conhecimentos como coletivos é retomado como prova de os 
mesmos serem de domínio público. Outro argumento é o de existirem patentes que, embora com usos idênticos aos tradicionais, tratam de produtos finais e métodos de extração diferentes, ou seja, seria necessário reconhecer a todos os que contribuíram para o estado da arte final, até o uso industrial e comercial atual (Dutfield, 1999). Fato é que a maioria perde no quadro atual, em sua própria mesa transgênica, não apenas as populações tradicionais, e que não há soluções convincentes em vista, sequer procurando reequilibrar saber tradicional e tecnologia empresarial. Monocultura em escala significa hierarquização da divisão do trabalho e da organização da produção social: a diversificação é ligada à auto-sobrevivência; a monocultura, à exportação e à dependência. Quanto mais distante o mercado consumidor, maior a especialização. Estocagem e escala têm seu papel na desigualdade, na centralização do poder político, financeiro e tecnológico, na redução da oferta de alimentos e na exploração irracional da natureza. Nada indica que se possa esperar por uma reversão da tendência à concentração, ou que os gargalos do mercado possam abrir oportunidades iguais às populações tradicionais e suas cooperativas, desqualificadas frente às transnacionais e aos acordos internacionais de comércio.

Notas

1 Família Myristicaceae. Esta planta é conhecida no Brasil por wana. Faz-se um tipo de rapé com a casca. Usada entre os Yanomami. Elisabesky, Elaine. Etnofarmacologia de algumas tribos brasileiras. In: Suma Etnológica Brasileira - 1 Etnobiologia. Petrópolis, Finep/Vozes, 1987, p. 137.

2 Banisteriopsis caapi (Spruce ex Griseb) Morton - Família Malpighiaceae. Origem: América do Sul.

3 Ainda pouco se sabe sobre esse veneno de flecha que poderia ser uma planta com propriedade curarizante, uma vez que é aplicado na ponta da flecha, derrubando o animal sem matá-lo. O animal cai devido a uma paralisia muscular. Agradeço a professora Maria Tereza de Arruda Camargo, ao professor Antonio Lamberti e Leopold Ródes por essas três notas em favor da interdisciplinaridade.

Referências bibliográficas

AB'SABER, A. Amazônia, do discurso à praxis. São Paulo, Edusp, 1996.

ANDERSON, A. \& POSEY, D. Manejo de cerrado pelos índios Kayapó. Belém, Boletim MPEG, Botânica, v.2, n.1, p.77-98, 1985.

CUNHA, M.C. Populações tradicionais e a Convenção da Biodiversidade Bioló- 
gica. In: Estudos Avançados, v. 13, n. 36, p.147-164, 1999.

DAVIS, S.H. Hard choices. Indigenous economic development and intellectual property rights. In: Akwe:kon Journal (Washington), p. 19-25, 1993.

DUTFIELD, G. The public and private domains: intellectual property rights in traditional ecological knowledge. Oxford Electronic Journal of Property Rights, 1999.

ESCURET, G.G. Les sociétes et leurs natures. Paris, Armand Collin, 1989.

GRAY, A. Between the space of life and the melting pot: biodivesity conservation and its impact on indigenous peoples. Copenhagen, IWGIA (doc. 70), 1991.

KAUFFMANN-ZEH, A. Faltam recursos para salvar a biodiversidade da Amazônia. Notícias Fapesp), n.42, p.10-12, 1999.

LEONEL, M. A morte social dos rios. São Paulo, Perspectiva, 1998.

. Exclusão e bio-sociodiversidade. Debates Socioambientais(Cedec), ano V, n.12, p.18-20, 1999.

Etnodicéia Uruenanau. São Paulo, Edusp, 1995.

MORÁN, E.F. A ecologia humana das populações da Amazônia. Petrópolis, Vozes, 1990.

NEVES, E.G. A arqueologia e a história das paisagens brasileiras. Debates Socioambientais (Cedec), Ano V, n. 12, p. 5, 1999.

NIJAR, G.S. The protection of cultural and biological biodiversity: legal and practical perspectives on developing sui generis options. Penang/Malasia, Third World Network, 1999.

NOVAES, W. Do Xingu a Kosovo. O Estado de S. Paulo, p.2, 18 jun. 1999.

OLIVEIRA, J.P. Fronteiras de papel. Humanidades, Brasília, UNB, 1988.

POSEY, D.A. Os Kayapó e a natureza. Ciência Hoje (SBPC), p.35-41, 1984.

RIBEIRO, B. Suma etnológica brasileira. Petrópolis, Vozes, 1987.

SANTOS, L.G. Tecnologia, natureza e a 'redescoberta do Brasil'. In: Araújo, H.R. (org.). Tecnociência e Cultura. São Paulo, Estação Liberdade, 1998.

SMITH, R.C. Amazonia: economia indigena y mercado. Quito, COICA/Oxfam America, 1996.

SHIVA, V. De quem é a biodiversidade? Terramérica, p.8-9, jun. 1999.

SIOLI, H. Fundamentos da ecologia da maior região de florestas tropicais. Petrópolis, Vozes, 1990.

TARDIEU, V. Guerra de patentes. Folha de S. Paulo, p. 5-13, 12 set. 1999. 
RESUMO - VÁRIOS estudos vêm revelando possibilidades de aproveitamento de conhecimentos indígenas e de outras culturas tradicionais, entre eles, medicamentos, cosméticos, novos materiais, alimentos, sementes e conservantes como produtos de mercado. A prática do mercado vem sendo a de apropriar-se desses bens culturais, registrá-los após adaptações e devolvê-los como mercadorias protegidas por patentes, inclusive aos países onde tais conhecimentos foram desenvolvidos, geralmente ao sul do Equador. Frente à escala da degradação social e ambiental, como na Amazônia, surgiu um novo otimismo, o de que resultados financeiros de tais produtos pudessem reverter às populações, modificando-se a legislação internacional e associando-se cooperativas de produtores com a biotecnologia e as transnacionais. $\mathrm{O}$ mercado, o principal adversário da preservação da bio e da sociodiversidade, seria assim convidado - empresas e consumidores - a tornar-se aliado da manutenção da floresta em pé e da diferença cultural, por exemplo, mediante certificados de origem. No entanto, são numerosos os entraves para que essas populações possam abrir brechas no mercado, ou nos sistemas internacionais de registro de patentes, frente à lógica da concentração de capital e tecnologia.

ABSTRACT - SEVERAL studies have been revealing prospects of capitalizing on native knowledge and traditional cultures in order to launch new market products, such as drugs, cosmetics, new materials, foods, seeds and preservers. The market has adopted the practice of appropriating such cultural goods, which after slight adaptation are registered and turned out as patent-protected products and sold even to the countries where that knowledge was first developed, south of the equator as a rule. Vis-à-vis the social and evironmental degradation scale, as is the case of the Amazon area, a new optimism has risen: the hope that financial results from such products could benefit the native peoples, through the alteration of international legislation and the association of producers cooperatives with transnational companies. The market, the main opponent of bio- and sociodiversity, would thus be invited - both producers and consumers - to support the maintenance of the standing forest and cultural difference, for example, by means of origin certificates. Nevertheless, many are the obstacles preventing the native peoples from making a breakthrough either in the market or in the patent registration international systems vis-à-vis the capital and technology concentration logic.

Mauro Leonel é professor-visitante do Instituto de Estudos Avançados da USP, professor do Procam (Programa de Pós-Graduação em Ciências Ambientiais da USP) e professor do Departamento de Ciências Políticas da Faculdade de Filosofia e Ciências da Unesp-Marília. É autor, entre outros, de A morte social dos rios, Perspectiva, 1998; Etnodicéia Umuéu-au-au, Edusp, 1995 e Roads, Indians and the Environment in the Amazon, from the Central Brazil to the Pacific. IWGIA, Copenhagen, 1992. 